\title{
Six-minute walk test and respiratory muscle strength in patients with uncontrolled severe asthma: a pilot study*
}

\author{
Teste de caminhada de seis minutos e força muscular respiratória em \\ pacientes com asma grave não controlada: um estudo piloto
Luiz Fernando Ferreira Pereira', Eliane Viana Mancuzo ${ }^{2}$, Camila Farnese Rezende ${ }^{3}$, Ricardo de Amorim Côrrea ${ }^{4}$

\begin{abstract}
Objective: To evaluate respiratory muscle strength and six-minute walk test (6MWT) variables in patients with uncontrolled severe asthma (UCSA). Methods: This was a cross-sectional study involving UCSA patients followed at a university hospital. The patients underwent 6MWT, spirometry, and measurements of respiratory muscle strength, as well as completing the Asthma Control Test (ACT). The Mann-Whitney test was used in order to analyze 6MWT variables, whereas the Kruskal-Wallis test was used to determine whether there was an association between the use of oral corticosteroids and respiratory muscle strength. Results: We included 25 patients. Mean $\mathrm{FEV}_{1}$ was $58.8 \pm 21.8 \%$ of predicted, and mean ACT score was $14.0 \pm 3.9$ points. No significant difference was found between the median six-minute walk distance recorded for the UCSA patients and that predicted for healthy Brazilians (512 m and $534 \mathrm{~m}$, respectively; $\mathrm{p}=0.14$ ). During the 6MWT, there was no significant drop in $\mathrm{SpO}_{2}$. Mean MIP and MEP were normal (72.9 $\pm 15.2 \%$ and $67.6 \pm 22.2 \%$, respectively). Comparing the patients treated with at least four courses of oral corticosteroids per year and those treated with three or fewer, we found no significant differences in MIP $(p=0.15)$ or MEP $(p=0.45)$. Conclusions: Our findings suggest that UCSA patients are similar to normal subjects in terms of 6MWT variables and respiratory muscle strength. The use of oral corticosteroids has no apparent impact on respiratory muscle strength.
\end{abstract}

Keywords: Asthma; Exercise tolerance; Respiratory muscles.

\section{Introduction}

Asthma is a chronic inflammatory disease of the airways characterized by bronchial hyperresponsiveness, variable airflow limitation, and symptoms such as dyspnea, wheezing, and cough, which improve spontaneously or with treatment. The primary goals of asthma treatment include complete symptom control, optimal management of limitations in activities of daily living, and reducing future risks. ${ }^{(1,2)}$ Most asthma patients have mild to moderate asthma, which is easily controlled with the use of inhaled corticosteroids (ICs) alone or in association with a long-acting $\beta_{2}$ agonist (LABA). ${ }^{(3)}$ However, among patients with severe asthma, there is a small subset of patients who remain symptomatic despite good adherence to treatment, correct use of inhalers, appropriate management of comorbidities, and use of high-dose ICs in association with LABAs, oral corticosteroids, omalizumab, or any combination of the three. ${ }^{(4,5)}$ Such patients are considered to have uncontrolled severe asthma (UCSA), which, according to current asthma guidelines, should be treated at specialized centers. ${ }^{(4,5)}$

Patients with UCSA require high-dose 1Cs alone or in association with oral corticosteroids, the adverse effects of which include decreased protein synthesis and increased protein degradation and contribute to muscle atrophy. ${ }^{(6)}$ In addition, increased airway resistance and lung hyperinflation also contribute to reducing inspiratory muscle

1. Preceptor. Pulmonology Outpatient Clinic, Federal University of Minas Gerais Hospital das Clínicas, Belo Horizonte, Brazil.

2. Professor. Federal University of Minas Gerais School of Medicine, Belo Horizonte, Brazil.

3. Resident in Pulmonology. Federal University of Minas Gerais Hospital das Clínicas, Belo Horizonte, Brazil.

4. Professor. Federal University of Minas Gerais School of Medicine, Belo Horizonte, Brazil.

*Study carried out at the Pulmonology Outpatient Clinic and in the Pulmonary Function Laboratory, Federal University of Minas Gerais Hospital das Clínicas, Belo Horizonte, Brazil.

Correspondence to: Luiz Fernando F. Pereira. Avenida do Contorno, 4747, sala 610, Funcionários, CEP 30110-921, Belo Horizonte, MG, Brasil.

Tel. 5531 3296-4041. E-mail: luizffpereira@uol.com.br

Financial support: None.

Submitted: 1 December 2014. Accepted, after review: 10 April 2015. 
efficiency, resulting in increased muscle work and energy expenditure to overcome airflow limitation. ${ }^{(7)}$ The aforementioned factors have yet to be well studied in patients with UCSA.

The six-minute walk test (6MWT) is a submaximal exercise test that evaluates the overall and integrated responses of all body systems involved in physical exercise, including the pulmonary system, the cardiovascular system, peripheral and systemic circulation, blood, neuromuscular units, and muscle metabolism. ${ }^{(8,9)}$ Respiratory muscle strength can be estimated from airway pressures generated by respiratory muscle contraction. Maximal static respiratory pressures are usually measured at the mouth during inhalation and exhalation, the former being designated MIP and the latter being designated MEP.(10)

The role of the 6MWT in the evaluation and follow-up of patients with COPD, interstitial lung disease, pulmonary arterial hypertension, and heart failure is well established. ${ }^{(8)}$ However, the only study evaluating the impact of severe asthma on the six-minute walk distance (6MWD) in adults was a study conducted by Canuto et al., ${ }^{(11)}$ who found that the 6MWD was significantly shorter in patients with difficult-to-control asthma (DCA) using oral corticosteroids than in healthy controls. In addition, although respiratory muscle strength (particularly MIP) has been reported to be reduced in several studies involving asthma patients, it has yet to be evaluated in patients with UCSA. ${ }^{(12)}$

The primary objective of the present study was to evaluate respiratory muscle strength and $6 \mathrm{MWT}$ variables in patients with UCSA. Secondary objectives were to evaluate the impact of oral corticosteroid use on respiratory muscle strength and to determine the correlation of the level of physical activity with the 6MWD and the level of asthma control in such patients.

\section{Methods}

This was a cross-sectional study of UCSA patients over 18 years of age treated at the Difficult-to-Control Asthma Outpatient Clinic of the Federal University of Minas Gerais Hospital das Clínicas, in the city of Belo Horizonte, Brazil, between September and December of 2012. The research project was approved by the Research Ethics Committee of the Federal University of Minas Gerais (ETIC Ruling no. 156.403/2012). All participants gave written informed consent.
The diagnosis of severe asthma was based on the American Thoracic Society/European Respiratory Society (ATS/ERS) criteria, ${ }^{(13)}$ as follows:

- major criteria-use of oral corticosteroids for at least six months per year and continuous use of high-dose 1Cs $(\geq 1,600 \mu \mathrm{g}$ of budesonide or equivalent) in association with LABAs

- minor criteria-FEV of < 80\%; PEF variability $>20 \%$; daily use of short-acting $\beta_{2}$ agonists; use of more than three courses of oral corticosteroids per year; history of near-fatal asthma; one or more emergency room visits in the previous year; and rapid decline in lung function after a decrease in the dose of corticosteroid therapy

The patients who were included in the present study received outpatient treatment for at least six months in order to control environmental factors and comorbidities, as well as to improve inhaler technique and treatment adherence. In addition, we included only patients assigned to Global Initiative for Asthma (GINA) and Brazilian Thoracic Association (BTA) asthma treatment step 4 or 5 (LABAs/high-dose 1Cs plus oral corticosteroids, anti-lgE treatment, or both) $)^{(1,2)}$ and meeting two major ATS/ERS criteria or one major and two minor ATS/ERS criteria. ${ }^{(13)}$ We excluded patients with severe heart disease; current smokers; former smokers who had a smoking history $\geq 10$ pack-years or who had quit smoking less than one year prior; and patients who had had exacerbations requiring emergency room treatment/hospitalization, use of prednisone or equivalent at doses above 20 $\mathrm{mg}$, use of antibiotics, or any combination of the three in the last four weeks.

The 6MWT was performed in a 25.6- $\mathrm{m}$ corridor with the use of a portable oximeter (Nonin Medical, Inc., Plymouth, MN, USA), in accordance with the recommendations of the ATS. ${ }^{(14)}$ Each of the participants underwent two 6MWTs, at least $30 \mathrm{~min}$ apart. We evaluated the following parameters: $\mathrm{SpO}_{2}$, as measured by pulse oximetry; HR; RR; and patient perception of dyspnea and leg fatigue, as assessed by Borg scale scores at the beginning and end of each test. In addition, we determined the percentage of the predicted maximal HR (\%HRmax) for adults, HR recovery at one minute after completion of the 6MWT $\left(H R R_{1}\right)$, and the 6MWD. Values of desaturation $\geq 4 \%,{ }^{(8,14)} \% \mathrm{HRmax}>85 \%$ of predicted, ${ }^{(8,14)}$ and 
$\mathrm{HRR}_{1}>12 \mathrm{bpm}$ were considered significant. ${ }^{(15-17)}$ The 6MWT during which the longest 6MWD was covered was considered valid; absolute and percent predicted 6MWD values were calculated by the reference equation for the 6MWD in the Brazilian population. ${ }^{(18)}$

Spirometry was performed with a Koko spirometer (PDS Instrumentation Inc., Louisville, CO, USA). The tests were performed and the results were interpreted in accordance with the BTA guidelines. ${ }^{(10)}$ All post-bronchodilator test results were reported as absolute values and as percentages of predicted values, in accordance with Pereira et al. ${ }^{(19)}$

Respiratory muscle strength was evaluated in accordance with the BTA guidelines, ${ }^{(10)}$ with a digital manometer (Warren E Collins lnc., Braintree, MA, USA), the signals being read and recorded through individual ducts. A 2-mm hole in the circuit prevented false measurements as a result of involuntary contractions of the cheeks. We measured MIP at RV and MEP at TLC. The results were expressed in $\mathrm{CmH}_{2} \mathrm{O}^{(20)}$

The level of asthma control was assessed with the Asthma Control Test (ACT), previously validated for use in Brazil, ${ }^{(21-23)}$ a score of 25 points indicating clinical remission of symptoms or totally controlled asthma, a score of 20-24 points indicating adequately controlled asthma, and a score of $<20$ points indicating uncontrolled asthma.

The level of physical activity was measured with the short version of the International Physical Activity Questionnaire (IPAQ), previously validated for use in Brazil. ${ }^{(24,25)}$ The instrument consists of seven questions regarding the frequency (in number of days per week) and duration (in number of minutes per day) of vigorous physical activity, moderate physical activity, and walking activity. On the basis of their IPAQ scores, individuals are classified as very active, active, irregularly active, or sedentary. In the present study, we divided the participants into two major groups: the group of very active/active individuals and the group of irregularly active/sedentary individuals. ${ }^{(24,25)}$

All study participants underwent chest HRCT for the differential diagnosis of other diseases, such as COPD, bronchiectasis, and allergic bronchopulmonary aspergillosis.

Data analysis was performed with the Statistical Package for the Social Sciences, version 18 (SPSS Inc., Chicago, ll, USA), and Minitab software, version 16 (Minitab Inc., State College, MA, USA). The Shapiro-Wilk test was used in order to evaluate the distribution of the data. Categorical variables were expressed as absolute and relative frequencies, and continuous variables were expressed as mean and standard deviation (parametric distribution) or as median and range (nonparametric distribution). The Mann-Whitney test was used in order to evaluate the difference between the 6MWD recorded for the patients with UCSA and that predicted for healthy individuals, as well as to evaluate the association of physical activity levels (IPAQ scores) with the 6MWD,

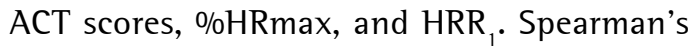
correlation test and the Kruskal-Wallis test were used in order to evaluate the association of oral corticosteroid use with MIP and MEP. Values of $p<0.05$ were considered statistically significant. On the basis of the longest 6MWD found in the literature (with a standard deviation of 90.44 $\mathrm{m}$ ) and using a level of significance of 0.05 and an unpaired two-tailed Student's t-test, we estimated that a sample size of 26 was needed in order to detect a difference of $50 \mathrm{~m}$ between the 6MWD found in the present study and that found in the literature. ${ }^{(26)}$

\section{Results}

The initial sample consisted of 29 patients. Three patients were excluded because of a probable overlap between asthma and COPD, and another one was excluded because of asthma exacerbation during the month of data collection.

The final sample consisted of 25 asthma patients (18 females and 7 males), their mean age being 49 years and their mean body mass index being $28.9 \pm 7.9 \mathrm{~kg} / \mathrm{m}^{2}$ (Table 1). All patients had ACT scores of $<15$ points, 14 (56\%) were classified as being irregularly active/sedentary, and $20(80 \%)$ had exercise limitation in the period between asthma attacks. Ten patients $(40 \%)$ had a history of exacerbations requiring ICU admission, and 7 (28\%) had a history of exacerbations requiring mechanical ventilation.

All patients were receiving treatment with LABAs and high-dose 1 Cs $(\geq 1,600 \mu \mathrm{gg}$ of budesonide or equivalent), 6 (24\%) had been using at least $10 \mathrm{mg} /$ day of prednisone for more than one year, and $3(12 \%)$ were using omalizumab.

The most common $\mathrm{CT}$ findings were bronchiectasis that was minimal/moderate and predominantly central, in 3 patients; small areas 
of centrilobular emphysema, in 11; mild right upper lobe fibrosis/atelectasis, in 1; and air trapping, in 1.

There was a predominance of obstructive lung disease (mean FEV, $58.8 \pm 21.8 \%$ of predicted), and 17 patients $(68 \%)$ had positive bronchodilator test results. Although mean MIP and MEP were

Table 1 - Baseline characteristics of the uncontrolled severe asthma patients studied. ${ }^{a}$

\begin{tabular}{lc}
\hline \multicolumn{1}{c}{ Characteristic } & $\mathrm{N}=25$ \\
\hline Age, years $^{\mathrm{b}}$ & $49.8 \pm 12.6$ \\
Female gender & $18(72)$ \\
$\mathrm{BMl}^{\mathrm{a}}{ }^{\mathrm{a}} \mathrm{kg} / \mathrm{m}^{2}$ & $28.9 \pm 7.9$ \\
Former smokers $^{\mathrm{c}}$ & $4(16)$
\end{tabular}

Activity limitations in the period between attacks

No limitations

Limitations in exercise performance

$20(80)$

Limitations in activities of daily living

$3(12)$

Limitations in self-care

Limitations at rest

Attacks in the previous year ${ }^{\text {d }}$

Systemic corticosteroid use during

$5(0-23)$

9 (36)

attacks ( $\geq 4$ courses/year)

Continuous oral corticosteroid use

Total number of hospitalizations ${ }^{\mathrm{d}}$

ICU admissions

$15(0-100)$

$10(40)$

7 (28)

History of CPA

$21(84)$

Comorbidities

$22(88)$

2 (8)

$13(52)$

11 (44)

2 (8)

4 (16)

4 (16)

2 (8)

1 (4)

1 (4)

Sequelae of tuberculosis

ABPA

$\mathrm{ACT}^{\mathrm{b}}$

$14.0 \pm 3.9$

Physical activities - IPAQ score

Active or very active

$11(44)$

Irregularly active or sedentary normal, $7(28 \%)$ and $11(44 \%)$ of the 25 patients studied had reduced MIP and MEP (of < 65\% of predicted), respectively (Table 2). Of the 7 patients who had reduced MIP, only 2 had spirometric signs of lung hyperinflation.

There was no significant difference $(p=$ 0.14 ) between the median 6MWD recorded for the UCSA patients in the present study-512 m (range, 307.2-597.3 $\mathrm{m}$ )-and that predicted for healthy individuals-534 m (range, 382.6-621.3 $\mathrm{m}$ )-(Figure 1).

None of the patients required supplemental oxygen and there was no significant decrease in mean $\mathrm{SpO}_{2}$ during the 6MWT; however, 5 patients experienced desaturation during the test. Of those, 2 experienced bronchospasm, which was reversed with the use of a shortacting $\beta_{2}$ agonist, 2 had comorbidities (allergic bronchopulmonary aspergillosis and sequelae of pulmonary tuberculosis), and 1 had evidence of emphysema and air trapping on chest CT scans. At the end of the 6MWT, perceived leg fatigue was mild and perceived dyspnea was mild to moderate. All patients had a significant decrease in $\mathrm{HRR}_{1}$ (Table 3).

When we compared the subset of patients treated with continuous oral corticosteroids or four or more courses of oral corticosteroids per year (n $=15$ ) with that of those treated with three or fewer ( $n=10$ ), in order to investigate the association between the frequency of oral corticosteroid use and respiratory muscle strength, we found no statistically significant differences in median MIP-74.5\% (range, 59.0-104.0\%) and 72.5\% (range, 43.0-104.0\%; $p=0.15$ ), respectively-or MEP-67.5\% (range, 29.0-121.0\%) and 63.5\% (range, 34.0-121.0\%; $\mathrm{p}=0.45$ ), respectively.

Table $\mathbf{2}$ - Spirometry results and maximal respiratory pressures in the uncontrolled severe asthma patients studied $(\mathrm{N}=25) .^{\text {a }}$

\begin{tabular}{lcc}
\hline \multicolumn{1}{c}{ Variable } & \multicolumn{2}{c}{ Result } \\
\cline { 2 - 3 } & Pre-BD & Post-BD \\
\hline FEV $_{1} \%$ of predicted & $58.8 \pm 21.8$ & $66 \pm 22.4$ \\
FEV $_{1}, \mathrm{~L}$ & $1.61 \pm 0.63$ & $1.81 \pm 0.62$ \\
FVC, \% of predicted & $83.4 \pm 20.7$ & $91.0 \pm 19.1$ \\
FVC, $\mathrm{L}$ & $2.79 \pm 0.71$ & $3.05 \pm 0.65$ \\
FEV & /FVC & $56.3 \pm 12.0$ \\
MIP, $\mathrm{cmH}_{2} 0$ & $-87.2 \pm 21.0$ \\
MIP, \% of predicted & $72.9 \pm 15.2$ \\
MEP, $\mathrm{cmH}_{2} 0$ & $108.3 \pm 42.9$ \\
MEP, \% of predicted & $67.6 \pm 22.2$ \\
\hline
\end{tabular}

BD: bronchodilator. ${ }^{\circledR}$ Values expressed as mean \pm SD. 
The 11 most physically active patients and the 14 least physically active patients were found to be similar in terms of their ACT scores, 6MWD, $\mathrm{HRR}_{1}$, and \%HRmax during the 6MWT (Table 4).

\section{Discussion}

Patients who do not achieve asthma control at GINA asthma treatment step 4 or 5 have historically been classified as having DCA.(1) However, debate over the most appropriate terminology has been ongoing for more than two decades because of the different criteria used in order to define severe asthma, DCA, refractory asthma, therapy-resistant asthma, and, more recently, UCSA.

In 2000, the ATS proposed criteria for defining DCA, and those criteria contributed to resolving part of the controversy. ${ }^{(13)}$ However, it was only after the publication of the 2013 ATS/ERS task force guidelines-ratified and cited in the 2014 GINA guidelines-that the classification of severe asthma became clearer. ${ }^{(4,5)}$

According to the aforementioned guidelines, the term "difficult-to-treat asthma" should be reserved for asthma in patients who are able to achieve better disease control after improving environmental hygiene, inhaler technique, treatment adherence, or comorbidity management. However, the same guidelines defined patients with "severe asthma" as those who, despite the aforementioned measures, required drugs assigned to GINA asthma treatment steps 4 and 5 in the last 12 months or systemic corticosteroids for at least 6 months in the last 12 months in order to maintain asthma control or those in whom the disease remained inadequately

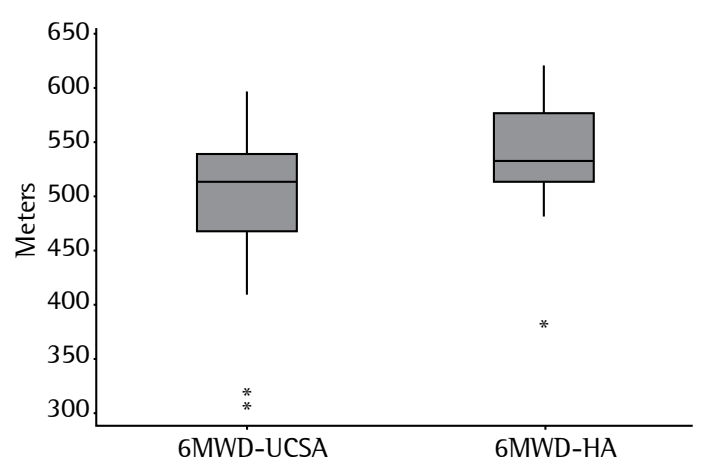

Figure 1 - Distribution of the six-minute walk distance (6MWD) in 25 patients with uncontrolled severe asthma (6MWD-UCSA) in comparison with the 6MWD predicted for healthy adults in Brazil (6MWD-HA). ${ }^{(18) a}$ *0utliers. aValues expressed in median. controlled despite treatment. ${ }^{(4,5)}$ Patients defined as having UCSA are those who, in addition to having poorly controlled asthma, meet at least one of the following criteria ${ }^{(4,5)}$ : an ACT score of $<20$ points or an equivalent score on any other validated instrument for assessing asthma control; two or more exacerbations requiring systemic corticosteroid use in the last year; severe exacerbation requiring hospitalization in the last year; and persistent airflow limitation despite GINA asthma treatment step 4 or $5 .^{(4,5)}$ Therefore, it is increasingly important to characterize UCSA patients and identify outcomes that can aid in evaluating the impact of interventions on such patients. Among such outcomes are exercise capacity and respiratory muscle strength.

In our study, the 6MWD recorded for the patients with UCSA was similar to that predicted for healthy Brazilians. ${ }^{(18)}$ In addition, the patients with UCSA had normal post-6MWT SpO $\mathrm{S}_{2}, \mathrm{HRR}_{1}$, and respiratory muscle strength.

It is known that the 6MWT provides indicators of functional capacity (the 6MWD), pulmonary gas exchange ( $\mathrm{SpO}_{2}$ ), cardiovascular stress (HR), cardiac automaticity $\left(\mathrm{HRR}_{1}\right)$, and sensory stress (dyspnea scores). ${ }^{\left({ }^{8}\right)}$ Although our patients were irregularly active or sedentary and had moderate obstructive lung disease and uncontrolled asthma, their mean 6MWD was $512 \pm 72 \mathrm{~m}$. In addition, mean desaturation was less than significant during the test $\left(\mathrm{SpO}_{2}\right.$ having decreased $<4 \%$ from baseline).

We found that \%HRmax was achieved in approximately $71 \%$ of the study participants, a

Table 3 - Six-minute walk test in the uncontrolled severe asthma patients studied $(\mathrm{N}=25)$. $^{\text {a }}$

\begin{tabular}{lcc}
\hline \multicolumn{1}{c}{ Variable } & $\begin{array}{c}\text { Before the } \\
\text { 6MWT }\end{array}$ & $\begin{array}{c}\text { After the } \\
\text { 6MWT }\end{array}$ \\
\hline $\mathrm{SpO}_{2}, \%$ & $96.1 \pm 1.1$ & $93.7 \pm 3.5$ \\
$\mathrm{HR}, \mathrm{bpm}$ & $81.8 \pm 16.7$ & $117.8 \pm 20.3$ \\
RR, breaths/min & $18.5 \pm 2.6$ & $30.4 \pm 5.5$ \\
$\begin{array}{l}\text { Borg scale score } \\
\text { (leg fatigue) }\end{array}$ & $0.1 \pm 0.4$ & $2.9 \pm 2.6$ \\
Borg scale score & $0.9 \pm 1.2$ & $4.7 \pm 1.9$ \\
(dyspnea) & & \\
6MWD, m & - & $512 \pm 4.2$ \\
HRR, bpm & - & $21.7 \pm 8.3$ \\
HRmax, \% & - & $71 \pm 11$ \\
\hline
\end{tabular}

6MWT: six-minute walk test; 6MWD: six-minute walk distance; HRR: $\mathrm{HR}$ recovery at one minute after completion of the 6MWT; and HRmax: predicted maximal HR. ${ }^{a}$ Values expressed as mean \pm SD. 
Table 4 - Association of the level of physical activity with the level of asthma control and six-minute walk test variables in the uncontrolled severe asthma patients studied $(\mathrm{N}=25) .{ }^{\text {a }}$

\begin{tabular}{|c|c|c|c|}
\hline \multirow[t]{3}{*}{ Variable } & \multicolumn{2}{|c|}{ Level of physical activity (IPAQ score) } & \multirow[t]{3}{*}{$\mathrm{p}$} \\
\hline & Very active or active & lrregularly active or sedentary & \\
\hline & $(n=11)$ & $(n=14)$ & \\
\hline 6MWD, m & $537.6(320.0-597.3)$ & $490.0(307.2-588.6)$ & 0.308 \\
\hline $\mathrm{HRR}_{1}$, bpm & $19.0(11.0-37.0)$ & $19.5(10.0-36.0)$ & 0.935 \\
\hline HRmax, \% & $72(53-89)$ & $73(50-84)$ & 0.621 \\
\hline ACT score & $15(7-17)$ & $13(6-24)$ & 0.144 \\
\hline
\end{tabular}

IPAQ: International Physical Activity Questionnaire; 6MWD: six-minute walk distance; HRR : HR recovery at one minute after completion of the six-minute walk test; HRmax: predicted maximal HR; and ACT: Asthma Control Test. ${ }^{a}$ Values expressed as median (range).

finding that indicates efficient gas exchange and adequate cardiovascular stress. Mean $\mathrm{HRR}_{1}(21.7$ $\pm 8.3 \mathrm{bpm}$ ) was significant, suggesting normal cardiac automaticity, although perceived leg fatigue and perceived dyspnea after completion of the 6MWT were moderate and somewhat strong, respectively. After reviewing the literature, we found only one study evaluating adults with severe asthma during the 6MWT. ${ }^{(11)}$ In that study, the 6MWD was significantly shorter in the group of patients with DCA than in the controls. ${ }^{(11)}$ However, the mean 6MWD in the group of patients with DCA was $435 \mathrm{~m},{ }^{(11)}$ which is approximately $112 \mathrm{~m}$ shorter than the 6MWD recorded for our sample of patients with UCSA. It is of note that the patients in that study were older than those in the present study $(52.3 \pm 8.3$ years vs. 49.8 \pm 14.4 years), had more severe obstruction, as shown by percent predicted FEV $(44.0 \pm 15.9 \%$ vs. $58.8 \pm 21.8 \%$ ), and used drugs that were more potent, such as oral corticosteroids (64\% vs. $24 \%$ ) and omalizumab (47\% vs. $12 \%$ ).

At the end of the 6MWT, there was a decrease in $\mathrm{SpO}_{2}$ in 5 of the 25 UCSA patients investigated in the present study. $\ln 2$, this was attributed to bronchospasm, which was rapidly reversed by rest and by using short-acting $\beta_{2}$ agonists. The remaining 3 had comorbidities (bronchiectasis due to sequelae of tuberculosis, allergic bronchopulmonary aspergillosis, and pulmonary emphysema with air trapping, respectively). These results suggest that, in the absence of bronchospasm, the presence of desaturation during the 6MWT in patients with UCSA should raise the suspicion of comorbidities.

According to one group of authors, ${ }^{(27)}$ the reasons for exercise limitation in patients with UCSA should be investigated and include asthma itself, alveolar hyperventilation, exercise-induced bronchoconstriction, physical deconditioning, submaximal test, and cardiac ischemia. The authors noted that, after the reasons for exercise limitation have been identified, treatment can be revised, particularly the use of high-dose corticosteroids in patients without pulmonary limitation. ${ }^{(27)}$

Respiratory muscle strength measurements (mean MIP and MEP) in the UCSA patients investigated in the present study were no different from those in healthy individuals. An increase in functional residual capacity (caused by lung hyperinflation) flattens the diaphragm and alters respiratory mechanics, resulting in a mechanical disadvantage, which can be inferred by a reduction in respiratory muscle strength. $(7,28)$ However, asthma patients with mild or moderate obstructive lung disease might not have significant lung hyperinflation resulting in changes in diaphragm position. ${ }^{(29,30)}$ The fact that the patients in the present study had moderate airway obstruction might explain why their MIPs and MEPs were similar to those in healthy individuals.

We found no significant differences in mean MIP and MEP between the asthma patients who often used oral corticosteroids and those who did not (i.e., those who were treated with three or fewer courses of oral corticosteroids per year). However, only 6 patients (24\%) were using oral corticosteroids continuously. One group of authors found that inspiratory muscle strength was lower in oral corticosteroid-dependent asthma patients than in asthma patients using high-dose $1 \mathrm{Cs}$, the level of lung hyperinflation being similar between the two groups of patients. ${ }^{(28)}$ It should be noted that MIP and MEP were found to be reduced in $28 \%$ and $48 \%$ of the patients, respectively. A reduction in respiratory muscle strength can occur, particularly in obese females, as a result of respiratory muscle dysfunction. Respiratory 
muscle activity can also be negatively affected by increased elastic resistance caused by the presence of excess adipose tissue in the rib cage and abdomen, which results in a mechanical disadvantage to the muscles. ${ }^{(31,32)} \ln$ our study, $72 \%$ of the patients were female, their mean body mass index being $28 \mathrm{~kg} / \mathrm{m}^{2}$.

Although the results of the present study should be interpreted with caution, particularly because of the lack of a control group, the small sample size, the cross-sectional study design, and the single-center nature of the study, they are relevant because of the lack of studies examining exercise capacity in patients with severe asthma and because of the difficulties in investigating exercise capacity in such patients. In addition, the present study is relevant because it examined a sample of patients treated at a referral center in a university hospital and because of its high statistical power (of 81\%).

In conclusion, the 6MWD recorded for the UCSA patients in the present study was found to be similar to that predicted for healthy Brazilians. The fact that there was a decrease in $\mathrm{SpO}_{2}$ in 5 of the 25 patients studied can be explained by the presence of bronchospasm and comorbidities. Respiratory muscle strength measurements (mean MIP and MEP) were found to be above the predicted lower limit, regardless of the use of oral corticosteroids. Further studies, involving a larger number of patients and including a control group, are needed in order to gain a better understanding of exercise capacity in patients with severe asthma and determine its role in the management of the disease.

\section{References}

1. Global Initiative for Asthma - GINA. [homepage on the Internet]. Bethesda: Global Initiative for Asthma. [cited 2012 Sep 11]. Global Strategy for Asthma Management and Prevention. Available from: www.ginaasthma.org

2. Cruz AA, Fernandes AL, Pizzichini E, Fiterman J, Pereira LF, Pizzichini M, et al. Diretrizes da Sociedade Brasileira de Pneumologia e Tisiologia Para o Manejo da Asma - 2012. J Bras Pneumol. 2012;38(Suppl 1):S1-S46.

3. Barnes PJ, Woolcock AJ. Difficult asthma. Eur Respir J. 1998;12(5):1209-18 http://dx.doi.org/10.1183/090 31936.98.12051209

4. Chung KF, Wenzel SE, Brozek JL, Bush MC, Sterk PJ, Adcock IM et al. International ERS/ATS guidelines on definition, evaluation and treatment of severe asthma. Eur Respir J. 2014;43(2):343-73. http://dx.doi. org/10.1183/09031936.00202013

5. Global Initiative for Asthma - GINA. [homepage on the Internet]. Bethesda: Global Initiative for Asthma. [cited
2014 Oct 1]. Global Strategy for Asthma Management and Prevention. Available from: www.ginaasthma.org

6. Schakman O, Gilson H, Thissen JP. Mechanisms of glucocorticoid-induced myopathy. J Endocrinol. 2008;197(1):1-10. http://dx.doi.org/10.1677/J0E-07-0606

7. Weiner P, Suo J, Fernandez E, Cherniack RM. Hyperinflation is associated with reduced strength and efficiency of the respiratory muscles in asthmatic and normal subjects. Chest. 1990;97(3 Suppl):69S-70S. http://dx.doi.org/10.1378/ chest.97.3_Supplement.69S-a

8. Morales-Blanhir JE, Palafox Vidal CD, Rosas Romero Mde J, García Castro MM, Londo-o Villegas A, Zamboni M. Six-minute walk test: a valuable tool for assessing pulmonary impairment. J Bras Pneumol. 2011;37(1):110-7. http://dx.doi.org/10.1590/S1806-37132011000100016

9. Enright PL, Sherrill DL. Reference equations for the six-minute walk in healthy adults. Am J Respir Crit Care Med. 1998;158(5 Pt 1):1384-7. http://dx.doi.org/10.1164/ ajrccm.158.5.9710086

10. Pereira CAC, Neder JA; Sociedade Brasileira de Pneumologia e Tisiologia (SBPT). Diretrizes para Testes de Função Pulmonar. J Pneumol. 2002;28(Suppl 3):1-238.

11. Freitas Canuto F, Silva SM, Malosá Sampaio LM, Stirbulov R, Ferrari Corrêa JC. Neurophysiological and functional assessment of patients with difficult-to-control asthma. Rev Port Pneumol. 2012;18(4):160-5. http://dx.doi. org/10.1016/j.rppneu.2012.02.008

12. Cavalcante Marcelino AM, Justino da Silva H. Role of maximal inspiratory pressure in the evaluation of respiratory muscle strength in asthmatics - Systematic review [Article in Portuguese]. Rev Port Pneumol. 2010;16(3):463-70. http://dx.doi.org/10.1016/S0873-2159(15)30042-8

13. Proceedings of the ATS workshop on refractory asthma: current understanding, recommendations, and unanswered questions. American Thoracic Society. Am J Respir Crit Care Med. 2000;162(6):2341-51. http://dx.doi.org/10.1164/ ajrccm.162.6.ats9-00

14. ATS Committee on Proficiency Standards for Clinical Pulmonary Function Laboratories. ATS statement: guidelines for the Six-Minute Walk Test. Am J Respir Crit Care Med. 2002;166(1):111-7. http://dx.doi.org/10.1164/ ajrcm.166.1.at 1102

15. Shetler K, Marcus R, Froelicher VF, Vora S, Kalisetti D, Prakash M, et al. Heart rate recovery: validation and methodologic issues. J Am Coll Cardiol. 2001;38(7):1980-7. http://dx.doi.org/10.1016/S0735-1097(01)01652-7

16. Cole CR, Blackstone EH, Pashkow FJ, Snader CE, Lauer MS. Heart-rate recovery immediately after exercise as a predictor of mortality. N Engl J Med. 1999;341(18):1351-7. http://dx.doi.org/10.1056/NEJM199910283411804

17. Jolly MA, Brennan DM, Cho L. Impact of exercise on heart rate recovery. Circulation. 2011;124(14):1520-6. http://dx.doi.org/10.1161/CIRCULATIONAHA.110.005009

18. Soares MR, Pereira CA. Six-minute walk test: reference values for healthy adults in Brazil. J Bras Pneumol. 2011;37(5):576-83.

19. Pereira CA, Sato T, Rodrigues SC. New reference values for forced spirometry in white adults in Brazil. J Bras Pneumol. 2007;33(4):397-406. http://dx.doi.org/10.1590/ S1806-37132007000400008

20. Black LF, Hyatt RE. Maximal respiratory pressures: normal values and relationship to age and sex. Am Rev Respir Dis. 1969;99(5):696-702.

21. Nathan RA, Sorkness CA, Kosinski M, Schatz M, Li JT, Marcus P, et al. Development of the asthma control test: 
a survey for assessing asthma control. J Allergy Clin Immunol. 2004;113(1):59-65. http://dx.doi.org/10.1016/j. jaci.2003.09.008

22. Roxo JP, Ponte EV, Ramos DC, Pimentel L, D’Oliveira Júnior A, Cruz AA. Portuguese-language version of the Asthma Control Test. J Bras Pneumol. 2010;36(2):159-66. http://dx.doi.org/10.1590/S1806-37132010000200002

23. Melosini L, Dente FL, Bacci E, Bartoli ML, Cianchetti $\mathrm{S}$, et al. Asthma control test (ACT): comparison with clinical, functional, and biological markers of asthma control. J Asthma. 2012;49(3):317-23. http://dx.doi. org/10.3109/02770903.2012.661008

24. Academia.edu [homepage on the Internet] [cited 2012 Jul 2]. Guidelines for data processing and analysis of the International Physical Activity Questionnaire (IPAQ) - Short and long forms contents. [Adobe Acrobat document, 15p.]. Available from: https://www.academia.edu/5346814/ Guidelines_for_Data_Processing_and_Analysis_of_the_ International_Physical_Activity_Questionnaire_IPAQ_ Short_and_Long_Forms_Contents

25. Pardini R, Matsudo S, Araújo T, Andrade E, Matsudo V, Braggion $\mathrm{G}$, et al. Validação do questionário internacional de nível de atividade física (IPAQ - versão 6): estudo piloto em adultos jovens brasileiros. Rev Bras Ciênc Mov. 2001;9(3):45-51.

26. Machin D, Campbell M, Fayers P, Pinol A. Confidence intervals. In: Machin D, Campbell M, editors. Sample size tables for clinical studies. 2nd ed. London: Blackwell Science; 1997; p.122.

27. McNicholl DM, Megarry J, McGarvey LP, Riley MS, Heaney LG. The utility of cardiopulmonary exercise testing in difficult asthma. Chest. 2011;139(5):1117-23. http:// dx.doi.org/10.1378/chest.10-2321

28. Akkoca 0, Mungan D, Karabiyikoglu G, Misirligil Z. Inhaled and systemic corticosteroid therapies: Do they contribute to inspiratory muscle weakness in asthma? Respiration. 1999;66(4):332-7. http://dx.doi.org/10.1159/000029403

29. Oliveira CM, Lanza Fde C, Solé D. Respiratory muscle strength in children and adolescents with asthma: similar to that of healthy subjects? J Bras Pneumol. 2012;38(3):30814. http://dx.doi.org/10.1590/S1806-37132012000300005

30. Decramer M, Lacquet LM, Fagard R, Rogiers P. Corticosteroids contribute to muscle weakness in chronic airflow obstruction. Am J Respir Crit Care Med. 1994;150(1):11-6. http://dx.doi.org/10.1164/ ajrccm.150.1.8025735

31. Levin OS, Polunina AG, Demyanova MA, Isaev FV. Steroid myopathy in patients with chronic respiratory diseases. J Neurol Sci. 2014;338(1-2):96-101. http:// dx.doi.org/10.1016/j.jns.2013.12.023

32. Weiner P, Waizman J, Weiner M, Rabner M, Magadle $\mathrm{R}$, Zamir D. Influence of excessive weight loss after gastroplasty for morbid obesity on respiratory muscle performance. Thorax. 1998;53(1):39-42. http://dx.doi. org/10.1136/thx.53.1.39 